\title{
TECNOLOGIAS EDUCACIONAIS PARA O ENSINO E A APRENDIZAGEM DE LIBRAS: ONDE ESTÃO OS RECURSOS EDUCACIONAIS ABERTOS?'1
}

\author{
Alan Ricardo Costa (UNISC) $)^{2}$
}

\begin{abstract}
RESUMO: O objetivo desta pesquisa é o de averiguar a presença (ou a ausência) de Recursos Educacionais Abertos (REAs) para o ensino e a aprendizagem de Língua Brasileiras de Sinais (Libras) em repositórios virtuais e em projetos no viés da Educação Aberta e do compartilhamento de materiais didáticos no Brasil. Com base no suporte teórico sobre produção colaborativa e compartilhamento de REAs (SANTOS, 2013; OKADA, 2014; COSTA, 2016), foram realizadas pesquisas exploratórias, de viés qualitativo, em 14 websites (repositórios ou websites de cursos online). Os resultados indicam a presença de poucos REAs para o ensino e a aprendizagem de Libras.
\end{abstract}

PALAVRAS-CHAVE: Recursos Educacionais Abertos. Libras. Material didático.

RESUMEN: El objetivo de esta investigación es el de averiguar la presencia (o la ausencia) de Recursos Educativos Abiertos (REAs) para la enseñanza y el aprendizaje de Lengua Brasileña de Señales (Libras) en repositorios virtuales y en proyectos referentes a la Educación Abierta y al compartimiento de materiales didácticos en Brasil. Con base en el soporte teórico sobre producción colaborativa y compartición de REAs (SANTOS, 201; OKADA, 2014; COSTA, 2016), se realizaron investigaciones exploratorias, de sesgo cualitativo, en 14 web sitios (repositorios o sitios web de cursos online). Los resultados indican la presencia de pocos REAs para la enseñanza y el aprendizaje de Libras.

PALABRAS CLAVE: Recursos Educativos Abiertos. Libras. Material didáctico.

\section{INTRODUÇÃO}

Nos últimos anos, uma proposta político-pedagógica tem crescido em nível global: o movimento para uma Educação Aberta (AMIEL, 2012, COSTA, 2017). Tal movimento tem como uma de suas principais bandeiras a (re)produção e o compartilhamento de Recursos Educacionais Abertos (REAs), ou Open Educational Resources (OERs), em inglês. De acordo com o conceito cunhado pela Organização das Nações Unidas para a Educação, a Ciência e a Cultura (UNESCO), REAs são materiais de ensino, aprendizagem e investigação, em quaisquer suportes, digitais ou outros, situados em domínio público e/ou divulgados com licença aberta para acesso, uso, adaptação e redistribuição gratuitos por terceiros, mediante nenhuma ou pouca restrição (UNESCO, 2012).

A Educação Aberta, por meio do fomento à produção colaborativa e ao uso compartilhado de REAs, tenta contribuir com a educação de forma geral. Para os professores, tal movimento permite pensar no trabalho conjunto, colaborativo e em rede (COSTA, 2016): docentes de todos os lugares do mundo podem compartilhar com seus pares diferentes tipos

\footnotetext{
1 Artigo produzido a partir do Trabalho de Conclusão de Curso intitulado "Recursos Educacionais Abertos (REAs) para o ensino e a aprendizagem de LIBRAS disponíveis na Web", defendido em 2018, para conclusão do curso de Pós-Graduação - Especialização em Libras, pela Universidade Católica Dom Bosco. Trabalho orientado pela profa. $\mathrm{M}^{\mathrm{a}}$. Nayara da Silva Cesario Martins.

${ }^{2}$ Doutorando do Programa de Pós-Graduação em Letras (PPGL) da Universidade de Santa Cruz do Sul. Mestre em Linguística Aplicada pela Universidade Católica de Pelotas. E-mail: alan.dan.ricardo@gmail.com
} 
de materiais didáticos. Além disso, epistemologias mais colaborativas e centradas na autonomia do aluno emergem, uma vez que os REAs, por serem abertos, podem ser adaptados e modificados para atender as necessidades educacionais específicas de cada estudante/contexto.

No que tange especificamente ao ensino e à aprendizagem de línguas, sejam elas maternas, sejam elas estrangeiras, os benefícios de um trabalho mediado por REAs também são notórios. Afinal, no séc. XXI, a educação está permeada por Tecnologias Digitais de Informação e Comunicação (TDICs) e tecnologias educacionais, e por meio delas podemos ter experiências de imersão linguística, contato direto com falantes e estudantes de línguas que desejamos aprender ou adquirir, e acesso a materiais de pesquisa e consulta (dicionários, gramáticas, enciclopédias, etc.), em variados formatos (texto, vídeo, animação, áudio, etc.) de forma rápida e gratuita, a partir de alguns clics.

É necessário especificar, contudo, que, para a efetivação da proposta de uma Educação Aberta, dois pontos são cruciais. O primeiro deles é a adesão do maior número possível de professores, pesquisadores e acadêmicos em geral, tendo em vista que esse é um movimento colaborativo. O segundo aspecto é a investigação da visibilidade de línguas geralmente negligenciadas em ações e projetos educacionais dos campos da Linguística e da Linguística Aplicada. Isto é: precisamos saber quantos e quais REAs temos para o ensino das mais diversas línguas no cenário nacional, que é tão complexo e rico em variedades linguísticas. É nesse ponto, então, que entra a questão da Língua Brasileira de Sinais (Libras). Precisamos saber, dos materiais acessíveis a professores e a alunos, quantos e quais servem para o ensino e a aprendizagem de Libras, tanto para surdos quanto para ouvintes.

Tendo em vista as considerações precedentes, este trabalho é desenvolvido com o objetivo geral de averiguar a presença (ou a ausência) de REAs para o ensino e a aprendizagem de Libras em repositórios virtuais e em projetos de Educação Aberta e compartilhamento de materiais didáticos no Brasil. Os objetivos específicos da pesquisa incluem: (a) mapear repositórios virtuais e projetos educacionais que contenham inventários de materiais didáticos e atividades para o ensino de Libras (como língua materna, estrangeira e/ou segunda língua); (b) avaliar, dentre os repositórios e projetos mapeados, a incidência de materiais didáticos e REAs que servem ao ensino e à aprendizagem de Libras, por parte de surdos e ouvintes; e (c) analisar os materiais encontrados em termos qualitativos no que tange ao público-alvo ao qual o material se destina e à abertura (possibilidade de adaptação e modificação no material). Para cumprir tais objetivos, foi realizada uma pesquisa com metodologia exploratória em repositórios digitais de REAs e websites com cursos online que possam contar com REAs para o ensino e a aprendizagem de Libras.

\section{A EDUCAÇÃO ABERTA E OS RECURSOS EDUCACIONAIS ABERTOS}

Para Costa (2016, p. 23), "A Educação Aberta é um movimento político de democratização do acesso ao conhecimento e de materiais de ensino, indissociável de discussões de cunho social, econômico, cultural, etc.". De acordo com Marzari (2014, p. 109), a proposta de uma Educação Aberta (Educación Abierta, Open Education) surgiu como resposta à Declaração de Educação da Cidade do Cabo (The Cape Town Open Education Declaration ${ }^{3}$ ), idealizada em setembro de 2007, durante um encontro realizado na cidade do Cabo, prevendo o uso disseminado da tecnologia no ensino, o que contempla o acesso aberto (facilitado) às TDICs e aos REAs.

\footnotetext{
${ }^{3}$ Disponivel em $<\underline{\text { http://www.capetowndeclaration.org/translations/portuguese-translation> }}$.
} 
O principal fator de popularização do movimento para uma Educação Aberta se dá pelos REAs, cuja característica principal é um conjunto de potencialidades adaptativas e de colaboração (LEFFA, 2016). Em título de ilustração, as principais potencialidades dos REAs, já elencadas em Costa (2016, p. 29), são inerentes à capacidade de:

1) Retenção: nível de abertura referente à possibilidade do usuário reter o material. Segundo Mazzardo, Nobre e Mallmann (2016), concerne ao direito de fazer e possuir cópias do conteúdo. Para tanto é necessário conhecer o conceito e características dos REAs, saber onde encontrar, selecionar, organizar um acervo e uma forma de acesso rápido, apropriar-se (considerando as licenças em jogo, evidentemente), etc.

2) Reuso: dimensão mais elementar de abertura. Permite aos usuários a reutilização, total ou parcial, do trabalho em distintos contextos, como no caso hipotético da reprodução de uma música, ou um refrão dela, em uma atividade de uma aula de francês. Mazzardo, Nobre e Mallmann (2016) lembram que o reuso também pode implicar (a) planejar e implementar atividades didáticas com REAs, (b) indicar como material de estudo complementar para os alunos, (c) usar REAs em metodologias ativas, como a sala de aula invertida (Flipped Classroom), entre outros.

3) Revisão: dimensão de abertura que garante adaptações no recurso, para atender às necessidades e às especificidades de cada contexto educacional; adaptações tais como a reformulação das instruções de uma atividade, a mudança da língua (português, inglês...) empregada em algum trecho do conteúdo, "a alteração da fonte em determinado trecho, reordenação das partes do material, entre outras modificações” (COSTA, 2016, p. 29).

4) Remixagem: dimensão de abertura referente à combinação de diferentes trabalhos. A remixagem permite que um professor possa, por exemplo, integrar uma atividade sua (uma música, por exemplo) com uma imagem disponível em um portal educacional e, ainda, complementada por questões dirigidas aos alunos, desenvolvidas por "outro professor, que mora em outro país e que trabalhou a mesma música, mas com outros objetivos, em um contexto educacional diferente" (COSTA, 2016, p. 29).

5) Redistribuição: o nível de abertura relacionado ao compartilhamento do recurso com terceiros. É o caso de um professor que envia aos alunos um arquivo aberto contendo questões de avaliações de anos anteriores daquela determinada matéria. Mazzardo, Nobre e Mallmann (2016) definem a característica de redistribuição como o direito de compartilhar cópias do conteúdo original e/ou revisados.

Cabe salientar, contudo, que não só de REAs vive a Educação Aberta. Além dos REAs, é necessário enfatizar o papel das Práticas Educacionais Abertas (PEAs). Santos (2013, p. 81) elucida que as PEAs "se referem ao uso institucionalizado de REAs". Trata-se, grosso modo, de um conjunto de atividades relacionadas à criação, ao uso e ao reuso dos REAs, segundo o conceito cunhado pelo OPAL Consortium (The Open Educational Quality Initiative), em 2010 (SANTOS, 2012).

A pesquisadora Alexandra Okada (2014), a partir de experiências e de pesquisas sobre (co)produção e uso de REAs, concluiu que existem níveis de coautoria possíveis, a partir de diferentes formas de reutilizá-los: tradução, versão, síntese, redesenho, remixagem, personalização, decomposição e outras (ver a Tabela 1, a seguir). 


\section{$=$ TRAMA $=$}

Tabela 1: Formas de reutilizar REAs e o respectivo nível de coautoria em questão.

\begin{tabular}{|c|c|c|}
\hline & $\begin{array}{l}\text { Níveis de } \\
\text { coautoria }\end{array}$ & Formas de reutilizar REAs \\
\hline \multirow{3}{*}{$\frac{0}{\frac{1}{4}}$} & \multirow{3}{*}{$\begin{array}{c}\text { Recriar o } \\
\text { conteúdo e } \\
\text { contribuir para, } \\
\text { adicionando sua } \\
\text { própria } \\
\text { interpretação, } \\
\text { novas produções }\end{array}$} & $\begin{array}{l}\text { Coautoria: Transformar o conteúdo, adicionando sua própria } \\
\text { interpretação, reflexão, prática ou conhecimento. }\end{array}$ \\
\hline & & $\begin{array}{l}\text { Contextualização: Alterar o conteúdo ou acrescentar novas } \\
\text { informações, a fim de atribuir significado, sentido através de } \\
\text { exemplo e cenários. }\end{array}$ \\
\hline & & $\begin{array}{l}\text { Redesenho: Converter um conteúdo num outro formato, ou } \\
\text { num modo de apresentação diferente. }\end{array}$ \\
\hline \multirow{3}{*}{ 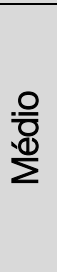 } & \multirow{3}{*}{$\begin{array}{l}\text { Adaptar parte do } \\
\text { conteúdo }\end{array}$} & $\begin{array}{l}\text { Síntese: Reduzir o conteúdo, selecionando as ideias } \\
\text { essenciais. }\end{array}$ \\
\hline & & $\begin{array}{l}\text { Reaproveitamento: Reutilizar para uma finalidade diferente ou } \\
\text { alterar para tornar mais adequado para diferentes objetivos. }\end{array}$ \\
\hline & & $\begin{array}{l}\text { Versão: Implementar mudanças específicas para atualizar o } \\
\text { conteúdo ou adaptá-lo para um contexto diferente. }\end{array}$ \\
\hline \multirow{3}{*}{$\frac{.}{\sqrt[x]{\widetilde{D}}}$} & \multirow{3}{*}{$\begin{array}{c}\text { Adotar o mesmo } \\
\text { conteúdo, mas } \\
\text { adaptar a } \\
\text { estrutura, o } \\
\text { formato ou o } \\
\text { idioma }\end{array}$} & Tradução: Transpor o conteúdo de um idioma para outro. \\
\hline & & $\begin{array}{l}\text { Personalização: Agregar tecnologias para contribuir com o } \\
\text { processo individual e personalizado. }\end{array}$ \\
\hline & & Reordenação: Alterar a ordem ou sequência. \\
\hline \multirow{3}{*}{$\frac{\text { 을 }}{z}$} & \multirow{3}{*}{$\begin{array}{c}\text { Adotar o mesmo } \\
\text { conteúdo (parte } \\
\text { total ou } \\
\text { combinação) }\end{array}$} & $\begin{array}{l}\text { Decomposição: Separar o conteúdo em diferentes seções, } \\
\text { quebrar o conteúdo em partes. }\end{array}$ \\
\hline & & $\begin{array}{l}\text { Remixagem: Conectar o conteúdo com novas mídias, } \\
\text { interfaces interativas ou componentes diferentes. }\end{array}$ \\
\hline & & $\begin{array}{l}\text { Montagem: Integrar o conteúdo com outros materiais a fim de } \\
\text { desenvolver um módulo ou uma nova unidade de curso. }\end{array}$ \\
\hline
\end{tabular}

Fonte: Okada (2014), adaptada por Costa (2016, p. 49).

Cada uma das formas de reutilizar REAs pode ser entendida como uma PEA. E cada uma delas pode servir à popularização da Libras enquanto língua a ser ensinada ou aprendida. Afinal, é possível pegar materiais de outras línguas, ou pensadas para determinados alunos e para determinados contextos educacionais, e adaptá-los para servir ao ensino ou à aprendizagem de Libras, para alunos surdos ou ouvintes, em contextos de escolas bilíngues, por exemplo.

\section{AS BARREIRAS LINGUÍSTICAS E A VISIBILIDADE DA LIBRAS}

De acordo com Amiel (2012), o movimento para uma Educação Aberta pode ser entendido como um conjunto de tentativas de buscar alternativas sustentáveis para romper barreiras no que tange ao direito de uma educação de qualidade. Por exemplo, barreiras econômicas (com materiais gratuitos e acessíveis) e geográficas (principalmente uma educação online, acessível mesmo à distância). Há outras barreiras, porém, e cada uma delas leva à necessidade de uma série de debates e de ações fundamentais para combater a desigualdade social no que diz respeito à educação. Aparenta ser cada vez mais urgente, nesse sentido, a ênfase na quebra de mais barreiras, que pode colocar em risco o movimento para uma Educação Aberta: barreiras de viés linguístico (ver COSTA, 2017).

Uma forma de pensar a questão das barreiras linguísticas - e, por contraste, a importância de uma abertura ao plurilinguismo - é a partir da promoção de projetos envolvendo REAs em países de terceiro mundo e não-falantes da língua inglesa, como Ucrânia, Azerbaijão, Rússia, Armênia e outros. Segundo Costa (2016, 2017), foi solicitado pela UNESCO, 
inicialmente, um relatório do estado da arte das ações de REAs em tais países. Posteriormente, o mesmo interesse foi expandido ao âmbito de países como Vietnã, Japão, China, Turquia e Brasil (SANTOS, 2013). A razão de tal interesse não é difícil de compreender: na perspectiva da(s) abertura(s), um movimento de fomento à (re)produção e à popularização dos REAs "fechar-se" e restringir-se aos países de primeiro mundo, cuja língua oficial seja o inglês, seria uma incoerência (COSTA, 2017). Os REAs devem se popularizar em todos os países, não apenas em função da contradição de uma iniciativa que se propõe aberta e transnacional restringir-se a um microssistema europeu-inglês, mas também em função dos benefícios que tais recursos podem levar aos vários contextos escolares ao redor do mundo (idem, ibidem).

Um exemplo bem-sucedido de abertura e democratização linguística é o projeto Wikipédia - desenvolvido por Jimmy Wales, empresário americano -, que se propõe a "ser uma enciclopédia aberta, online, multilíngue, produzida a partir de colaboração em rede" (COSTA, 2017, p. 14). Conforme o próprio website do projeto aponta, na Wikipédia, todos os participantes são voluntários, sem um líder específico, e todos os membros coordenam seus esforços e fazem suas contribuições. Praticamente todo o conteúdo da Wikipédia é apresentado em inúmeras opções de línguas, podendo ser acesso a partir da escolha de seu usuário. Há algum tempo, a Wikipédia já contava com mais de 280 opções de línguas. Tal número possivelmente já aumentou (COSTA, 2016; 2017).

Quando falamos em conteúdo, é preciso destacar: não só o material da Wikipédia está em línguas variadas, mas também seu design. Toda e qualquer parte da Wikipédia que não esteja apresentada em determinada língua pode passar a sêlo a partir da colaboração de seus usuários. Internautas podem criar novas páginas, traduzir conteúdo para outras línguas, expandir o material a línguas e dialetos variados, etc. Esse tipo de abertura, presente em um maior número de repositórios e projetos de REAs, contribuiria expressivamente para a quebra de barreiras linguísticas e, consequentemente, aumentaria o número de opções de materiais, inclusive para estudos contrastivos, comparações entre línguas e variedade cultural (COSTA, 2017, p. 14, 15).

Mas quantos projetos são tão plurilinguísticos e abertos a novas línguas quanto a Wikipédia? Aparentemente, não muitos. Consideremos o seguinte: por meio da popularização da Educação Aberta, cada vez mais tem sido fomentado o investimento em (1) software livre, (2) licenças de abertura (como aquelas de Creative Commons), (3) projetos de coaprendizagem e co-investigação, (4) práticas abertas, colaborativas e em rede, e (5) repositórios virtuais de publicação e compartilhamento de REAs. Muitos desses softwares, repositórios e projetos, todavia, não estão (ao menos por enquanto) devidamente abertos às variadas línguas, nem contemplam as muitas línguas de cada contexto social. Muitos ainda contam apenas com materiais e interfaces em inglês, contribuindo para uma hegemonia dessa língua ante muitas outras ainda negligenciadas. Então, o que devemos buscar, no movimento para uma Educação Aberta, é fôlego para expandir os horizontes do meio acadêmico a uma maior variedade de línguas, não só para fins de democratização e horizontalidade dos contextos linguísticos, mas também pela potencialidade que a interculturalidade e a riqueza linguística almejada podem proporcionar à educação (COSTA, 2017). Professores e estudantes brasileiros não precisam do inglês mais do que de quaisquer outras possíveis línguas estrangeiras ou segundas línguas. Todas as línguas podem e devem ser valorizadas e divulgadas (idem, ibidem). 


\section{$=$ TRAMA $=$}

É nesse sentido que a Libras merece mais espaço e visibilidade, enquanto língua reconhecida das comunidades surdas do Brasil, de acordo com a Lei N $10.436^{4}$, de 24 de abril de 2002. A Libras é a língua legítima de comunicação e expressão de comunidades de surdos no Brasil e, portanto, também deve estar presente em materiais pedagógicos como os REAs (COSTA, 2017). É necessário averiguar se já há estudos e relatórios e, principalmente, materiais abertos para o ensino e a aprendizagem de Libras, sobretudo nos repositórios digitais vinculados ao Ministério da Educação (MEC) e a outros órgãos institucionais.

Andreia Inamorato Santos, professora-pesquisadora da Open University, representando o Brasil, elaborou para a UNESCO relatório referente aos REAs e repositórios online e projetos educacionais envolvendo materiais didáticos abertos (SANTOS, 2011). Posteriormente, tal relatório foi publicado na forma de e-book intitulado O Estado da Arte, Desafios e Perspectivas para o Desenvolvimento e Inovação (SANTOS, 2013), para fins de divulgação dos projetos REAs no cenário nacional. A referida pesquisadora, nas obras mencionadas, elencou 14 projetos envolvendo REAs e os apresentou brevemente. Dentre esses, podemos considerar: (a) quais contam com um inventário de materiais didáticos para o ensino de línguas, seja materna, seja estrangeira, seja segunda língua? E (b) destes com alternativas de REAs para o ensino de línguas, quantos contemplam a Libras e as línguas de sinais de modo geral? Tais questionamentos, mais específicos, nos levam a outros, mais amplos: quais REAs que servem ao ensino e à aprendizagem de Libras temos, hoje, na internet? Dentre os repositórios digitais e projetos de REAs, quais contam, em seus inventários, com materiais para o ensino e a aprendizagem de Libras para estudantes surdos e ouvintes? É o que necessitamos, com urgência, apontar em pesquisas acadêmicas.

\section{METODOLOGIA}

A presente pesquisa foi desenvolvida a partir de três procedimentos metodológicos, os mesmos empregados por Costa, Py e Fialho (2017) para o mapeamento e a análise de REAs para o ensino e a aprendizagem de espanhol, a saber: (1) a delimitação de um corpus de pesquisa, (2) a delimitação de uma metodologia de coleta de dados, e (3) a realização das análises dos materiais selecionados, para discussão e encaminhamentos.

Para a seleção do corpus da pesquisa, as publicações de Santos $(2011,2013)$ serviram como base. Para a autora (SANTOS, 2013), o Brasil conta com os seguintes projetos e repositórios de REAs ou de materiais abertos: (1) Bibvirt-LabVirt - Rede Interativa Virtual da Educação; (2) Rede Interativa Virtual da Educação (RIVED); (3) Banco Internacional de Objetos Educacionais (BIOE); (4) Projeto Folhas; (5) OpenCourseware Unicamp/Universidade Estadual de Campinas; (6) Matemática Multimídia; (7) Projeto Condigital; (8) Portal Domínio Público; (9) Portal do Professor; (10) SENAI Cursos de Educação a Distância; (11) Portal da Secretaria Municipal de Educação de São Paulo; (12) Serviço Brasileiro de Apoio às Micro e Pequenas Empresas (Sebrae); (13) Fundação Getúlio Vargas (FGV); e (14) REA Dante.

Com base na pesquisa de Costa, Py e Fialho (2017), o corpus do estudo foi dividido em dois grupos: (1) o grupo de repositórios abertos de recursos didáticos, e (2) o grupo de portais e websites de cursos online envolvendo REAs. Foram considerados corpus da pesquisa no grupo referente aos websites/repositórios e portais abertos os projetos a seguir: (1) BibvirtLabVirt - Rede Interativa Virtual da Educação; (2) Rede Interativa Virtual da Educação (RIVED);

\footnotetext{
${ }^{4}$ Tal Lei determina também que o sistema educacional federal e estaduais, municipais e do Distrito Federal devem garantir a inclusão nos cursos de formação de Educação Especial, de Fonoaudiologia e de Magistério, em seus níveis médio e superior, do ensino da Língua Brasileira de Sinais - Libras, como parte integrante dos Parâmetros Curriculares Nacionais (PCNs).
} 
(3) Banco Internacional de Objetos Educacionais (BIOE); (4) OpenCourseware Unicamp; (5) Matemática Multimídia; (6) Projeto Condigital; (7) Portal Domínio Público; e (8) Portal do Professor. Por conseguinte, foram analisados como websites/plataformas de cursos abertos os seguintes projetos elencados por Santos (2011; 2013): (1) Projeto Folhas; (2) SENAI Cursos de Educação a Distância; (3) Portal da Secretaria Municipal de Educação de São Paulo; (4) Serviço Brasileiro de Apoio às Micro e Pequenas Empresas (Sebrae); (5) Fundação Getúlio Vargas (FGV); e (6) REA Dante.

O procedimento metodológico adotado foi o método exploratório: visita aos repositórios e aos cursos online, mapeamento (por meio dos motores de busca) de exemplares de recursos didáticos ou cursos abertos e, por fim, acesso e análise dos materiais encontrados (ver COSTA, PY e FIALHO, 2017). As buscas nos repositórios foram realizadas entre os meses de maio e junho de 2018.

\section{DADOS COLETADOS, ANÁLISES E DISCUSSÕES}

Novamente com base no estudo de Costa, Py e Fialho (2017), os resultados da investigação foram divididos, seguindo o parâmetro da separação do corpus da pesquisa, em dois grupos: (1) Análise dos repositórios abertos; e (2) Análise dos cursos online.

\section{ANÁLISE DOS REPOSITÓRIOS ABERTOS}

Os repositórios Bibvirt-LabVirt - Rede Interativa Virtual da Educação, atualmente coordenado pela Faculdade de Educação da Universidade de São Paulo (USP), e Matemática Multimídia, compilação de recursos educacionais multimídia desenvolvida pela UNICAMP, não contam com materiais para o ensino de Libras. No caso, o primeiro repositório conta com duas opções de tipos de materiais: aqueles voltados para a área de Física e aqueles voltados para a área de Química. O segundo repositório é voltado apenas para o ensino de matemática. Nesses repositórios, também não foram localizados materiais voltados ao ensino de conteúdos dessas disciplinas em Libras (como um material sobre 'logaritmos' em Libras, por exemplo).

Os dois repositórios analisados na sequência - o RIVED e o Portal Domínio Público apresentam um dado que deve ser registrado. Ambos, vinculados ao Ministério da Educação, e, portanto, com a responsabilidade social de respeitar o status político da Libras enquanto língua oficial do país, apresentam opções de línguas nos campos de busca. Isto é: ao fazer uso da ferramenta de busca dentro dos repositórios, o internauta pode selecionar a língua que deseja. A imagem a seguir (Imagem 1) é a captura de tela que mostra as opções de "línguas" dos materiais nos referidos repositórios, não sendo "Libras" uma das alternativas, infelizmente.

Imagem 1: Opções de línguas dos recursos dos repositórios RIVED e Domínio Público.

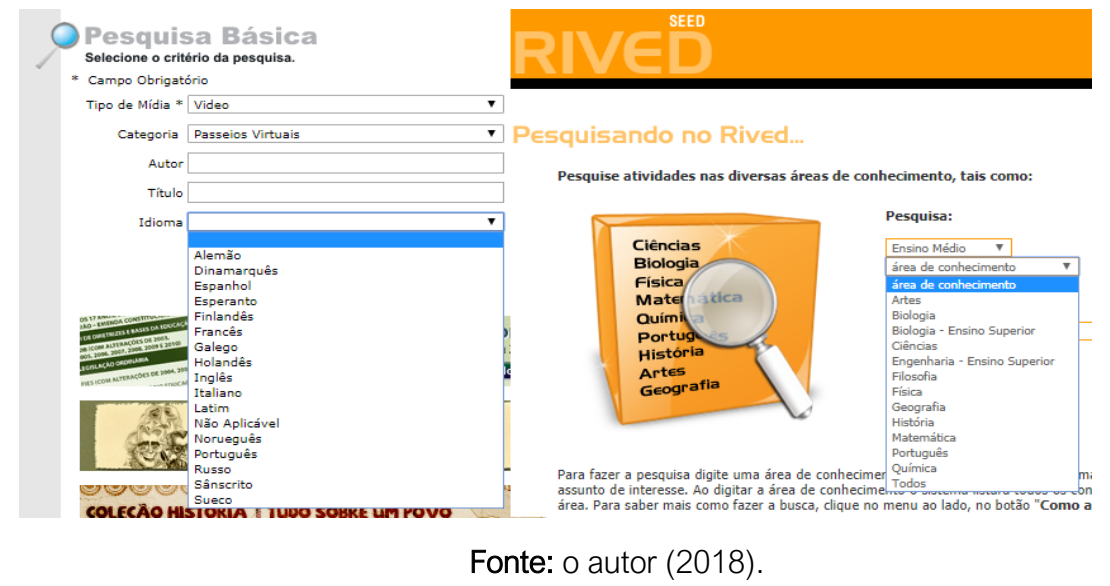




\section{$=$ TRAMA $=$}

No caso do RIVED, também não foram localizados materiais para o ensino de Libras. No caso do Portal Domínio Público, algumas opções de recursos foram localizadas. Em modo de ilustração, na seção de vídeos, há alguns documentários - como "Paulo Freire Contemporâneo", de 2006, dirigido por Toni Venturi. Esse tipo de material é bastante válido, e felizmente conta com interpretação em Libras. O mesmo vale para os demais recursos digitais, como as vídeo-aulas adaptadas com intérpretes de Libras.

O BIOE - "criado em 2008 pelo Ministério da Educação em parceria com: o Ministério de Ciência e Tecnologia, a Rede Latino-americana de Portais Educacionais (RELPE), a Organização dos Estados Ibero-americanos e outros" (SANTOS, 2013, p. 48) -, quinto repositório analisado, conta com materiais para o ensino de Libras, conforme mostra a imagem a seguir (Imagem 2). Contudo, os materiais localizados apresentam problemas de formato, pois demandam softwares específicos para serem executados. Nesse sentido, vale apostar no uso de materiais online, que não demandem download e programas específicos para o funcionamento.

Imagem 2: Busca por materiais no BIOE.

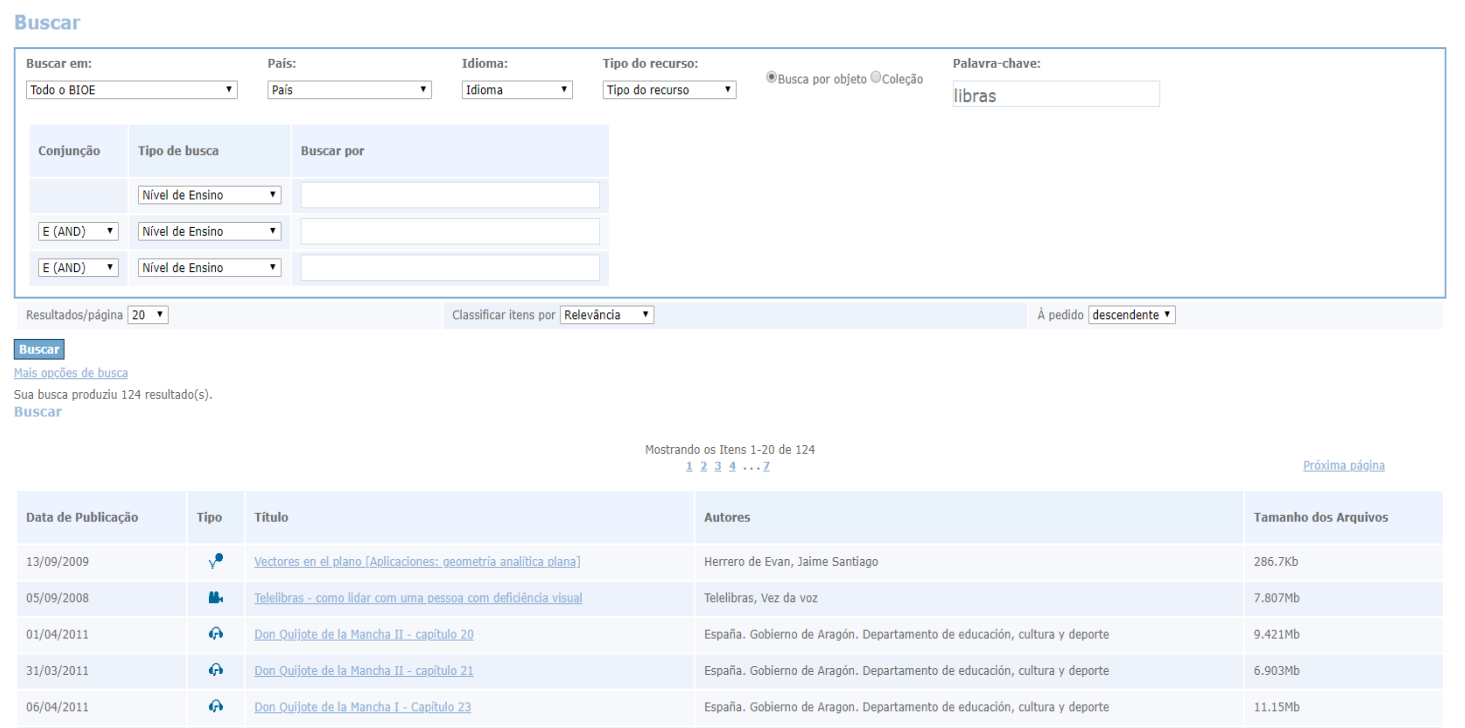

Fonte: o autor (2018).

No caso do Portal do Professor, nota-se que os materiais divulgados são mais voltados à contínua formação docente (artigos, ensaios, cursos de capacitação, etc.). Alguns poucos recursos são apresentados na forma de atividades para serem usadas com os alunos. Entretanto, na seção "cursos e materiais", ao selecionar "materiais", o usuário encontra a seção "Educação Inclusiva", que conta com materiais de apoio à educação inclusiva. Dentre esses materiais, há uma série de livros, por exemplo, em Libras.

Finalmente, temos o projeto Condigital, que atualmente não é um repositório online em si, mas um projeto de produção de recursos encomendados para disponibilização no BIOE e no Portal do Professor, segundo Santos (2013, p. 58), razão pela qual foi desconsiderado.

Assim, para sistematizar os resultados, é apresentada a tabela a seguir (Tabela 2), com a situação de cada repositório no que tange à presença de materiais para o ensino de (ou em) Libras. 


\section{$=$ TRAMA $=$}

Tabela 2: Repositórios online brasileiros elencados por Santos (2013).

\begin{tabular}{|c|c|c|}
\hline $\mathrm{N}^{\circ}$ & Nome do repositório online & Materiais em Libras? \\
\hline 1 & Bibvirt-LabVirt - Rede Interativa Virtual da Educação & Não \\
\hline 2 & Rede Interativa Virtual da Educação (RIVED) & Não \\
\hline 3 & Banco Internacional de Objetos Educacionais (BIOE) & Sim \\
\hline 4 & OpenCourseware Unicamp & Não \\
\hline 5 & Matemática Multimídia & Não \\
\hline 6 & Projeto Condigital & Sim \\
\hline 7 & Portal Domínio Público & Sim \\
\hline 8 & Portal do Professor & \\
\hline
\end{tabular}

Fonte: o autor (2018).

\section{ANÁLISE DOS CURSOS ONLINE}

De modo geral, os resultados são ainda mais pessimistas no caso de websites que hospedam ou servem de Ambiente Virtual de Aprendizagem (AVA) de cursos online. Em praticamente todos os casos, não foram localizadas opções de cursos de formação online ou capacitação em Libras, conforme pode ser constatado na imagem a seguir (Imagem 3), que mostra a ausência de resultados nas buscas orientadas pela palavra-chave "Libras" no website REA Dante, "iniciativa de recursos educacionais abertos do Colégio Dante Alighieri, em São Paulo" (SANTOS, 2013, p. 65), e do Serviço Nacional de Aprendizagem Industrial (SENAI).

Imagem 3: Busca por materiais no BIOE e no website do SENAI.

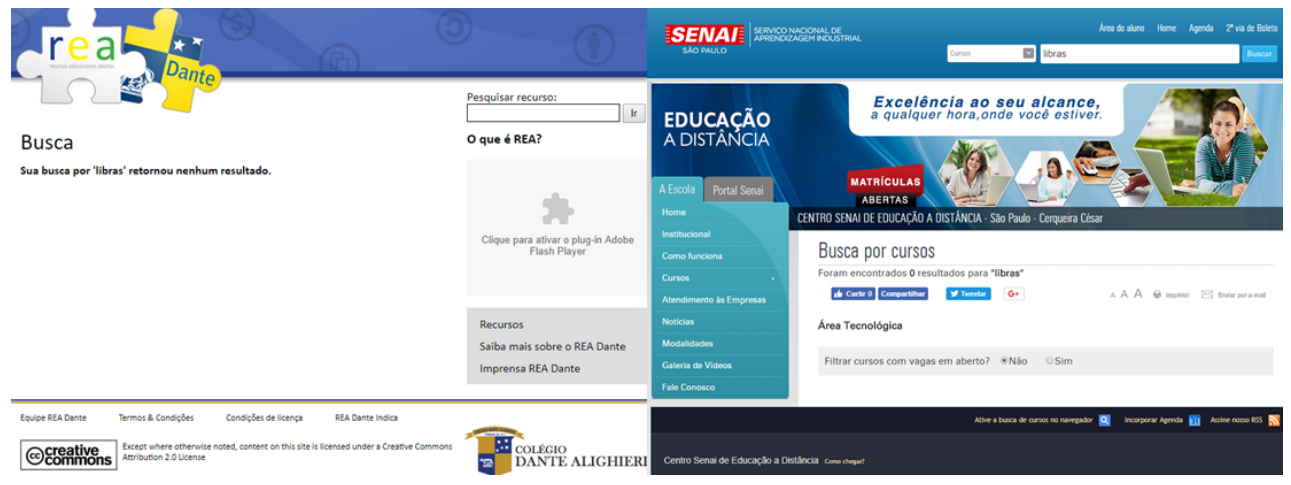

Fonte: o autor (2018).

Dentre os websites de cursos de capacitação e formação online, apenas o Portal da Secretaria Municipal de Educação de São Paulo apresenta resultados positivos. Sobre ele, Santos (2013) elucida:

A Secretaria Municipal de Educação de São Paulo implementou em seu site a licença Creative Commons 3.0 Brasil em junho de 2011. O site dá acesso a publicações que visam em sua maioria o ensino básico, destinadas a professores e alunos. Essas publicações incluem livros didáticos com foco em Português e Matemática, bem como diretrizes para professores sobre as expectativas de aprendizagem dos alunos. As Secretarias de Educação de outros municípios e estados agora podem usar esses recursos educacionais, adaptando-os às suas necessidades locais. Possivelmente, isso representaria uma economia significativa de dinheiro público investido, de um modo geral, na produção de materiais didáticos. Há uma necessidade, no entanto, de conscientizar os interessados e o público em geral de que esses recursos agora podem ser reutilizados (SANTOS, 2013, p. 62). 


\section{$=$ TRAMA $=$}

Além de materiais na forma de imagens, que podem ser usadas para o ensino e a aprendizagem de Libras, o portal conta também com notícias sobre eventos propostos para aprendizado de Libras e sobre a cultura surda, o que é considerado positivo em termos de divulgação e popularização de informações sobre a referida língua e o povo surdo.

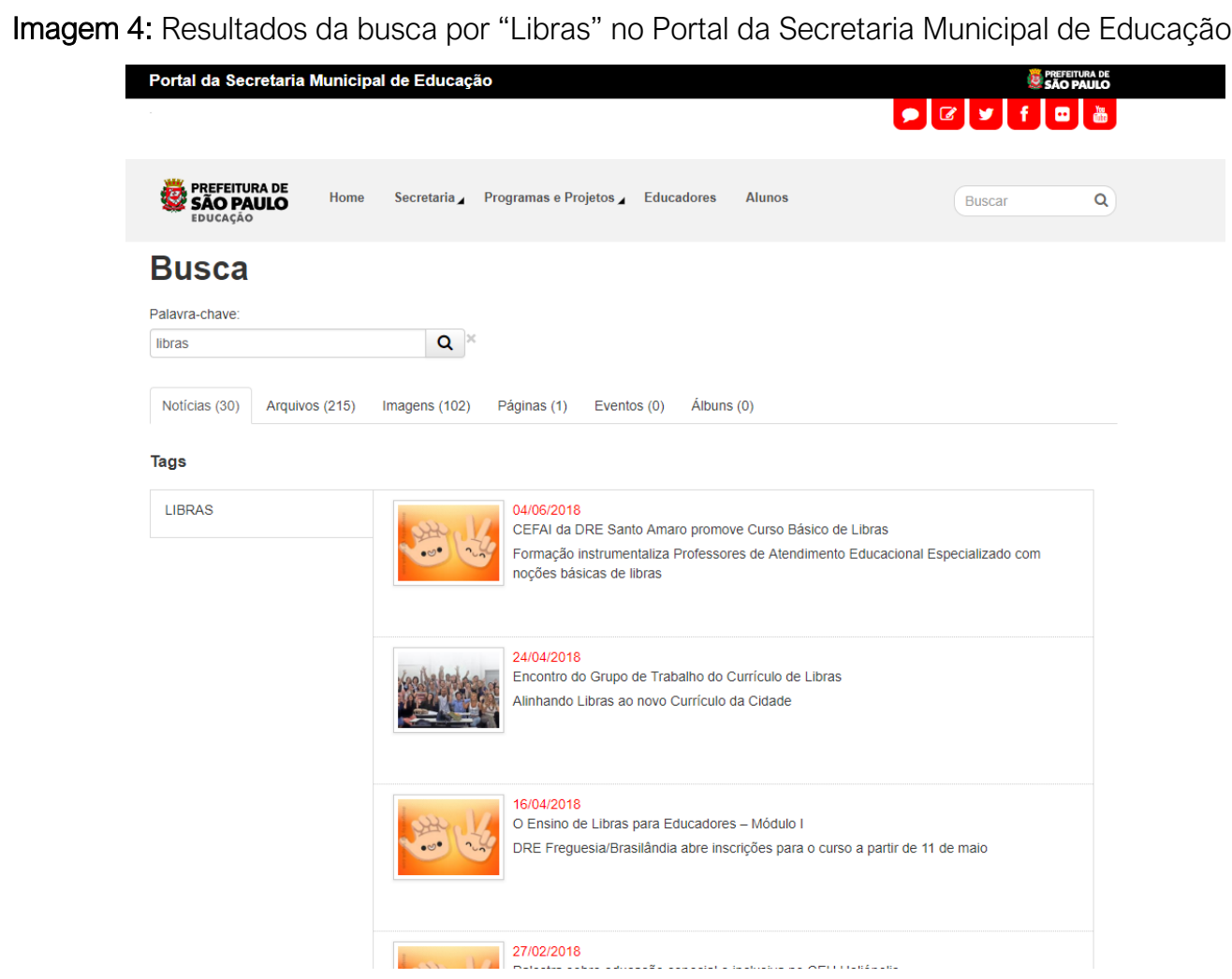

Fonte: o autor (2018).

A tabela a seguir (Tabela 3) sintetiza os resultados das buscas.

Tabela 3: Websites brasileiros de cursos online elencados por Santos (2013).

\begin{tabular}{|c|c|c|}
\hline N $^{\circ}$ & Nome do website & Cursos de Libras? \\
\hline 1 & Projeto Folhas & Não \\
\hline 2 & SENAI Cursos de Educação a Distância & Não \\
\hline 3 & Portal da Secretaria Municipal de Educação de São Paulo & Sim \\
\hline 4 & SEBRAE & Não \\
\hline 5 & Fundação Getúlio Vargas (FGV) & Não \\
\hline 6 & REA Dante & Não \\
\hline
\end{tabular}

Fonte: o autor (2018).

\section{CONSIDERAÇÕES FINAIS}

O objetivo maior do presente trabalho foi o de averiguar a situação dos materiais didáticos online para o ensino e a aprendizagem de Libras, na forma de REAs e recursos abertos online, nos repositórios e nos websites do cenário brasileiro. De modo geral, os resultados apontam para, ainda, um baixo número de materiais para a aprendizagem de Libras, e pouca divulgação dos materiais que já temos.

Para além da constatação do problema, com a presente pesquisa, foi possível também vislumbrar duas possíveis soluções para a ausência de materiais didáticos em (ou para) o ensino 
de Libras. A primeira alternativa é o investimento no movimento para uma Educação Aberta, sobretudo na exploração do potencial de abertura dos REAs. Enquanto materiais abertos à adaptação, mesmo aqueles materiais que não são voltados ao ensino e à aprendizagem de Libras podem passar a sê-lo. A maleabilidade e adaptatividade de materiais no meio virtual, somados às aberturas dos REAs (LEFFA, 2016), nos permitem ver um futuro não muito distante repleto de materiais que abordem a Libras na Web. Para isso, o movimento como um todo demanda maior adesão de professores, estudantes e autores de materiais de ensino.

A segunda alternativa é a aposta nos Sistemas de Autoria Aberto (SAA), conceito recentemente cunhado por Beviláqua et al. (2017) para dar conta de categorizar as ferramentas de autoria online para a criação de materiais didáticos (na forma de jogos online, webexercícios, webquests e atividades de outras naturezas). Resumidamente, um SAA é um sistema que permite a criação de atividades didáticas online, mas baseado nos princípios da colaboração em massa e desenvolvido para facilitar a produção, a adaptação e o licenciamento dos REA. Funciona como um website que automatiza a parte das configurações, dos códigos e da informática em geral, e deixa para o professor a parte do trabalho didático, criativo e educacional de pensar uma atividade que sirva para o ensino e a aprendizagem, como no caso hipotético do professor que quer criar um "jogo da memória" a partir de um software que possibilita ao aluno "virar a cartinha" do jogo e aprender com o conteúdo dela. Além dessa criação, um SAA permite que tal trabalho seja também compartilhado e adaptado por outros professores: algum docente que queira adaptar esse mesmo jogo da memória para que ele passe a servir ao ensino de Libras, conseguirá fazê-lo de modo bastante prático.

Em suma, ainda que os materiais para o ensino e a aprendizagem de Libras ainda sejam escassos e raros na Web, o futuro pode ser promissor. Isso porque alguns conceitos emergentes, como os de REA, Educação Aberta e SAA, nos permitem, cada vez mais, não só sonhar com, mas também efetivar uma, internet repleta de materiais para o ensino e a aprendizagem de Libras e, por conseguinte, uma internet mais democrática, plurilíngue, e que preze pela diversidade linguística e pela inclusão. Em minha opinião, enquanto professor e pesquisador diretamente envolvido com o ensino de línguas (materna ou estrangeira, primeira ou segunda), para alunos ouvintes e surdos, sinto diariamente, na práxis, a necessidade de produzir e compartilhar entre colegas docentes e estudantes mais recursos didáticos para o ensino e a aprendizagem de Libras, para que tal língua se popularize e ocupe no cenário nacional o status e o espaço que lhe é devido.

\section{REFERÊNCIAS}

AMIEL, Tel. Educação aberta: configurando ambientes, práticas e recursos educacionais. In: SANTANA, Bianca; ROSSINI, Carolina; PRETTO, Nelson de Lucca. (Org.). Recursos Educacionais Abertos: práticas colaborativas e políticas públicas. Salvador: Edufba, 2012.

BEVILÁQUA, André Firpo; LEFFA, Vilson José; COSTA, Alan Ricardo; FIALHO, Vanessa Ribas. Ensino de Línguas Online: um Sistema de Autoria Aberto para a produção e adaptação de Recursos Educacionais Abertos. Calidoscópio, vol. 15, n 1. 2017.

COSTA, Alan Ricardo. Identificando e rompendo mais barreiras no movimento para uma Educação Aberta: reflexões para (e com) professores de línguas. In: FAGUNDES, Angelise; ZIESMANN, Cleuza Inês. (Org.).

Construindo a profissão: a formação de Professores de Línguas e Literaturas. Santa Maria: Editora/Gráfica Caxias, 2017, p. 9-30.

COSTA, Alan Ricardo. Professores de línguas "na" e "em" rede? Formação continuada de educadores para práticas abertas de (re)produção de materiais didáticos online. 2016. 146 f. Dissertação (Mestrado em Linguística Aplicada) - Programa de Pós-Graduação em Letras, Universidade Católica de Pelotas, Pelotas, RS, 2016.

COSTA, Alan Ricardo. PY, Lorena Oliveira; FIALHO, Vanessa Ribas. Opções em recursos educacionais abertos para o ensino de espanhol no Brasil. Hipertextos - Revista Digital, v. 17. Recife. p. 82-96, 2017. 
LEFFA, Vilson José. Uma outra aprendizagem é possível: colaboração em massa, recursos educacionais abertos e ensino de línguas. Trabalhos em Linguística Aplicada. Campinas, nº 55/2, p. 353-377, 2016. MARZARI, Gabriela Quatrin. "Quem me ensinou o inglês que eu ensino?": a influência das tecnologias digitais na constituição da identidade do professor de línguas do século XXI. 2014. 228 f. Tese (Doutorado em Linguística Aplicada) - Programa de Pós-Graduação em Letras, Universidade Católica de Pelotas, Pelotas, RS, 2014.

MAZZARDO, Mara Denise; NOBRE, Ana; MALLMANN, Elena Maria. Professores efetivando os 5Rs de abertura dos Recursos Educacionais Abertos. a-Revista de Educação para o século XXI, v. 2, p. 1-10, 2016. OKADA, Alexandra. Competências chave para coaprendizagem na Era digital: fundamentos, métodos e aplicações. Santo Tirso: Whitebooks, 2014.

SANTOS, Andréia Inamorato dos. Educação Aberta: histórico, práticas e contexto dos Recursos Educacionais Abertos. In: SANTANA, Bianca; ROSSINI, Carolina; PRETTO, Nelson de Lucca. (Org.). Recursos

Educacionais Abertos: práticas colaborativas e políticas públicas. Salvador: Edufba, 2012.

SANTOS, Andréia Inamorato dos. Open educational resources in Brazil: state of the art, challenges and prospects for development and innnovation. Moscow: UNESCO, 2011.

SANTOS, Andréia Inamorato dos. Recursos Educacionais Abertos no Brasil: o estado da arte, desafios e perspectivas para o desenvolvimento e inovação. São Paulo: Comitê Gestor da Internet no Brasil. 2013. UNESCO. Declaração REA de Paris em 2012. UNESCO, Paris, 20 jun. 2012.

Recebido em 21-12-2018

Aceito em 22-04-2019 